\title{
Increase of Healthy Food Quality among the Kazakhstan Population
}

\author{
Z. Yessimsiitova ${ }^{1}$, N. Ablaikhanova ${ }^{1}$, S. Sagyndykova ${ }^{3}$, G. Tussupbekova ${ }^{1}, M^{2}$ Kulbayeva ${ }^{1}$, \\ G. Atanbayeva ${ }^{1}$, M. Aitzhan ${ }^{2}$ and Z. Bissenbayeva ${ }^{1, *}$ \\ ${ }^{1}$ Kazakh State National University of al-Farabi, Almaty, Kazakhstan \\ ${ }^{2}$ LLP «SPTC Zhalyn» \\ ${ }^{3}$ Atyrau State University of Kh. Dosmukhamedov, Kazakhstan
}

\begin{abstract}
At present, one of the most important urgent issues is the study of healthy nutrition of the population of Kazakhstan. Proper nutrition ensures the growth and development of children, contributes to the prevention of diseases, increase the capacity for work and prolong the life of people, while creating conditions for adequate adaptation to the environment.

Most of the population of Kazakhstan because of technological processing, the use of inadequate food raw materials, influence of other causes, does not receive the necessary amount of essential components of food, which lead to illnesses, premature aging and shortening of life.

The situation aggravates by the low cultural level of the population in matters of rational nutrition and the lack of skills for healthy lifestyles.

In this regard, the main task in the work was to study methods of improving the health and quality of life of the population of Kazakhstan, especially those living in zones of environmental problems and contacting with harmful factors.
\end{abstract}

Keywords: Functional ingredients, positive nutrition products, milk and dairy products, meat and meat products, enrichment, environment.

\section{INTRODUCTION}

Modern science considers balanced rational nutrition as one of the main elements of prevention and treatment of diseases. The most important condition for maintaining health is the body's ability to adapt to environmental conditions, to mitigate the impact of negative factors. However, the burden on the body is constantly increasing, and its capabilities are often limited.

Nutrition and health go inextricably together, so to increase the reserve capabilities of man, his resistance to the action of various negative factors is able to rational balanced nutrition, rich in all necessary, including essential nutrients. Along with this, even the supply of all the necessary nutrients does not guarantee health if the food contains dangerous factors of biological, chemical and physical nature that are the cause of the development of food poisoning and other violations of the normal functioning of the body. Therefore, for each person who cares about his health, it is necessary to have a general idea of these factors [1].

*Address correspondence to this author at the Kazakh State National University of al-Farabi, Almaty, Kazakhstan; Tel: +77073851878;

E-mail: zhanat_2006@mail.ru
Scientific research has shown that in recent years nutrition in the population has been reducing consumption of food sources of energy and protein, especially in low-income groups. At the same time, many people who are obese are identified, which is a consequence of metabolic disorders.

Significantly increased cardiovascular diseases, cancer, diabetes, stroke, cataract and glaucoma, osteoporosis, diseases of the brain, nervous system and others. Cardiovascular and oncological diseases are of special concern. The nature, level and structure of nutrition, which have a number of very serious violations largely determines the health of modern man.

Violation of the structure of nutrition is the main factor causing irreparable, several orders of magnitude stronger than environmental pollution, damage to our health. Over the past 10 years, the prevalence of the painful digestive system among schoolchildren has increased by 3.3 times, which is also directly related to nutritional deficiencies.

Scientists have found that such diseases are largely related to unbalanced nutrition; often depend on the addictions in eating an individual. Now it is already proved that some foodstuffs, when consumed in large quantities, can influence many vital functions of the 
organism and, in combination with harmful habits, hereditary predisposition and ecological ill health, contribute to the onset of diseases. The reason is the content of substances in food products that are among the risk factors. The place of positive nutrition researchers define, as the average between the usual diet and dietary nutrition. In addition to consumer properties, functional products have the properties of physiological effects.

The main species is recognized as a positive effect on the metabolism of various substrates, maintaining the energy balance, maintaining body weight, glucose level, insulin, protection against compounds with oxidative activity [2].

\section{DISCUSSION}

Activating the defenses of the body, normalize the metabolism and function of the digestive system allows a correct, healthy diet, which in this case is a powerful preventive agent. The shortage of time for most people has caused a disturbance in the rhythmic intake of nutrients, led to a qualitative and quantitative disturbance of the diet and, as consequence, to the energy imbalance. Modern man consumes more calories than he spends, his diet is mainly dominated by refined foods and semi-finished products, which after industrial processing are deprived of many essential nutritional factors (vitamins, microelements, dietary fiber, etc.), contain preservatives and other harmful impurities necessary for preservation of the presentation of the product [3].

At the same time, it is known that the provision of normal vital activity of the body is possible provided it is supplied not only with adequate amounts of energy and protein, but also by observing sufficiently strict interrelations between the numerous irreplaceable nutritional factors that play a specific role in the metabolism. One of the most common biological patterns is the enzyme sets of the organism, corresponding to the chemical structures of food, which are the cause of many diseases. Modern medical science also adopted the concept of optimal nutrition.

As part of the development of optimal nutrition, a new direction of functional proper nutrition has been formed, which includes the development of theoretical foundations, production, sales and consumption of functional products enriched with vitamins, minerals, trace elements. Despite the abundance of functional foods, the first product to be given this status belonged directly to the dairy group [4].
Kazakhstan traditionally produces a wide range of fermented milk products, a significant part of which was occupied by fermented milk products produced with acidophilic lactic acid rods. Clinical trials of these products have shown their high therapeutic and prophylactic effects in various gastrointestinal diseases. In fact, these were the first sour-milk products, which, according to the currently accepted terminology, are called probiotic foods. Interest in products aimed at normalizing the composition or increasing the biological activity of normal intestinal micro flora is increasing every year. Products that have new qualitative characteristics and differ in composition, biological and energy value, are also interesting as objects of standardization [5].

Methods for obtaining products of functional nutrition of animal origin are considered, for example, their enrichment with vitamins and dietary fibers.

The products of functional nutrition can be confidently called the products of positive nutrition, as they include functional ingredients that have a positive effect on individual functions of the human body or the body as a whole. Milk and dairy products, being a source of functional ingredients such as riboflavin and calcium, at the same time serve as a good basis for obtaining positive food products by adding bifido bacteria, minerals, dietary fiber, fat-soluble vitamins $A$, $D, E[6]$.

Meat and meat products are one of the most difficult bases for creating functional foods, although from the point of view of healthy nutrition, meat, along with vegetables, fruits and dairy products, is one of the most important foodstuffs. Thus, if we talk about the functionality of meat products, then they need to be enriched with vitamins. Meat and meat products are one of the main sources of vitamins of group B - B1, $\mathrm{B} 2, \mathrm{PP}$, others are very necessary for human vitamins $A, D, E, K, C, H, B 6, B 12$ - or there are no meat products, or be kept in small quantities. In order to expand the assortment of functional products, much attention is paid to the development of new functional products, in particular, enriched with vitamins, namely through the use of secondary raw materials, whey, and vegetable raw materials [7].

Food fibers are usually enriched with bakery, pasta, culinary, confectionery, etc. Meat products with food fibers are enriched to a lesser extent. Homemade bread makers are the basis of many people's food, bread is seen as a source of life and a symbol of work. The bread contains many nutrients a person needs, 
among them protein carbohydrates, vitamins, minerals, dietary fiber. In baked bread without enrichers, the content of such essential amino acids as lysine, Lucien, isoleucine, methionine, phenylalanine, threonine, tryptophan and valine is not enough. Therefore, the introduction of protein concentrators into the bread formula - milk, whey and soy, containing a large number of these amino acids, contributes to the increase in the nutritional value of bread. Due to grain products, a person almost completely covers the need for iron, receives a significant proportion of manganese and phosphorus. A significant disadvantage of the mineral bread complex is the low calcium content and its unfavorable relationship with phosphorus and magnesium. The bread in insufficient quantities contains potassium, chrome, cobalt and some other elements. However, in the latter there is a positive experience of enriching meat, dairy, bakery products with animal and plant-derived dietary fiber, useful properties that contribute to disease prevention and health promotion [8].

The scientific and technical policy of the state of the Republic of Kazakhstan in the field of nutrition is aimed at strengthening the health of the people. The basic principles of the state policy in the field of healthy nutrition is human health, the rational nutrition of children, as well as the state, their health, should be the subject of special attention of the state. In connection with the continuing pollution of air, reservoirs and soils, food should help protect the human body from unfavorable environmental conditions. Nutrition should not only meet the physiological needs of the human body in nutritional substances and energy, but also perform preventive and curative tasks. In recent years, the so-called functional nutrition, which means the systematic use of food products, which regulates the organism as a whole or its individual systems and organs, is widely used throughout the world. All products can be divided into two large groups: general purpose and functional food.

Products of functional nutrition include products with specified properties, depending on the purpose of their use. Functional are food products intended for systematic use in food rations, preserving and improving health, reducing the risk of development, food-related diseases, the presence in their composition of food functional ingredients that have the ability to have beneficial effects on one or more physiological functions and metabolic reactions human body. The main direction of the state policy of
Kazakhstan in the field of healthy nutrition is the creation of technologies for the production of qualitatively new food products, including massconsumption products for various age groups of the population, including children of different ages and elderly people, pregnant and lactating women, workers of industrial enterprises of various professional groups.

In addition, the creation of domestic production of food and biologically active additives, vitamins, and minerals in the amounts sufficient to ensure the full provision of the population, in particular, by enriching them with mass consumption products, is among the main directions of the state policy in the field of healthy nutrition [9].

\section{CONCLUSION}

Consequently, today more than ever in the food industry and public catering is the problem of creating products that have a curative and preventive effect. One of the ways to eliminate scarce conditions and increase the body's resistance to unfavorable environmental factors is the systematic use of foods enriched with a complex of biologically active additives with a wide range of therapeutic effects.

In Kazakhstan, programs are being developed on the organization of industrial production of mass consumption products and prophylactic purposes on dairy and grain bases with the addition of natural enterosorbent dietary fibers with directed detoxifying properties. This reduces the risk of poisoning the body with heavy metal salts, radio nuclides, pesticides and improve the quality of life for both adults and the children's population.

New methods will be used to synthesize the materials and the nature of the raw materials, such as the dynamics of the change in the texture characteristics of porous carbon materials, depending on the regime parameters of carbonization of plant raw materials, followed by activation by different methods and the nature of plant polymers.

The process of scientific and technical level will provide the opportunity to obtain new enterosorbent dietary fibers of a wide range. The synthesized enterosorbent dietary fibers have an optimal pore structure in the macro - meso - and nan scale region. This determines the universality and speed of the drug, its high sorption capacity and low dose of application, which is very necessary for the formation of a living organism and is one of its foundations for its 
functioning and use in effective prevention for various poisoning, allergies, intestinal infections, skin diseases, intoxication of various origins.

\section{REFERENCES}

[1] Kochetkova AA, Tuzhilkin VI, Nesterova IN, Kolesnov AYu, Voitkevich ND. Nutrition Issues 2000; 4.

[2] Gayazova AO, Rebezov MB, Pauls EA, Akhmedyarova RA, Kosolapova AS. Perspective directions of development of production of meat semi-finished products. The Young Scientist 2014; 9(68): 127-129.

[3] Dogareva NG, Stadnikova SV, Rebezov MB. Creation of new types of products from raw materials of animal origin and non-waste technologies for their production. University procedia as a regional center of education, science and culture. Orenburg, 2012; pp. 945-953.
[4] Raikina EYu, Dodonkin YuV. Theory of Commodity Science. M.: Academy, 2005.

[5] Teplov VI, Seroshtan MV, Boryaev VE, Panasenko VA. Commercial Merchandising A Textbook. - Third ed. - M. Publishing House "Dashkov and Co., 2005.

[6] Timofeeva VA. Commodity research of food products: Textbook. - Rostov n / a.: Phoenix, 2008.

[7] Zinina OV, Rebezov MB. Technological methods of modification of collagen-containing by-products. Meat Industry 2012; 5: 34-36.

[8] Goroshchenko L. Bread and bakery products. Food Business 2006; 8.

[9] Zinina OV, Rebezov MB, Solovyova AA. Biotechnological processing of meat raw materials. V. Novgorod: Novgorod Technopark 2013; p. 272. 